\title{
Whole-Genome Sequencing in Diagnostic Medicine: Too Much Information for Doctors and Patients?
}

\author{
Wolfram Henn \\ Institute of Human Genetics, Saarland University, Homburg/Saar, Germany
}

The introduction of novel diagnostic technologies with increased cost-efficiency usually gives rise to either higher diagnostic accuracy for existing indications or extension of the indication spectrum or both. In the context of genome analysis, the advent of next-generation DNA sequencing vastly enhances the amount of raw genetic data generated per sample, with the resulting question of how to reasonably apply the additional information.

It would be an unequivocal progress if large-scale sequencing could serve to a more precise resolution of existing diagnostic challenges, like exhaustive differential diagnosis of heterogeneous genetic disease. As an example, hereditary motor and sensory neuropathy (HMSN) can be caused by mutations within more than ten different genes, many of which account for very rare but clinically indistinguishable subtypes of the disease.

In such a case, cost-efficient sequencing of more candidate genes than currently feasible would only have the effect of enhanced chances to identify the mutation responsible for the clinically recognized disease within the given family, i.e., it would mean improved differential diagnosis. As such a singledisease multigene approach refers to a clinical condition wellknown to the investigated patient, the requirements to pre-diagnostic patient information and informed consent would remain the same as in technically conventional genetic diagnosis.

Much more problematic would be an multiparametric approach to simultaneous sequencing of a wide spectrum of susceptibility genes that might be involved in possible future disease of the patient. This would not mean diagnosis of a present medical condition but rather unselective predictive screening.

As an example, whole-genome sequencing in any healthy person might reveal a $B R C A 1 / 2$ mutation conferring a highrisk status for breast/ovary cancer with an a priori probability of about 1 in 200, or a heterozygous CFTR mutation conferring a carrier status for cystic fibrosis with an a priori probability of as much as 1 in 20 . With the huge number of late-onset or recessive genetic diseases in mind, it should be expected that the complete genome sequencing of any given person would reveal one or several disquieting, perhaps even unwelcome pieces of information.

According to the well-established WHO standards [1], reasonable medical screening depends on some core criteria: The addressed condition must be medically important, accessible to accurate diagnosis before the onset of symptoms, and successfully preventable or treatable. Moreover, any medical diagnosis, be it genetic or not, requires patient information about the specific condition to be tested for, without which no valid informed consent is possible. As for genetic traits, it is universally accepted that predictive diagnosis must be embedded in a process of genetic counselling with particular respect to the disease for which the patient is at risk.

Consequently, a medically sound and ethically acceptable use of a person's more or less complete genomic DNA sequence for individual disease prevention and health promotion would have to fulfill the following prerequisites:

- The raw sequence data must be error-free and subject to rigid quality control.

- The medical significance and predictive value of each sequence variant communicated to the proband - be it a disease-causing monogenic trait or a susceptibility variant for multifactorial disease - must have been sufficiently validated through clinical studies. Only sequence variants with high phenotypic penetrance should be communicated at all.

- The proband must have been thoroughly counselled prior to the test about its goals and limitations, in particular about the probabilistic nature of most genotype-phenotype relationships and about the medical and psychosocial effects of 'hard' predictive information that might arise.

\section{KARGER}

Fax +497614520714

Information@Karger.de

www.karger.com (c) 2009 S. Karger GmbH, Freiburg

Accessible online at:

www.karger.com/tmh 
- As a legal prerequisite to informed consent to testing, the pre-test counselling must separately comprise each addressed field of diagnosis. This means that the proband should agree not just globally to some dull kind of 'genetic profile', but precisely and selectively to getting information of variable predictive value about his or her risk of several types of cancer, neurodegenerative disorders, cardiovascular disease, and so on.

To be short, a scenario of selling a 'thousand-dollar genome' [2] to uncounselled buyers perhaps via the internet, who then are confronted with, say, a high-risk status for hereditary colon cancer due to an $M L H 1$ mutation, or even a carrier status for a fatal neurodegenerative disease like Huntington's, is totally unacceptable.

Currently, several companies like 23andMe, deCodeMe, and others already market single nucleotide polymorphism(SNP)based genetic screening tests via the internet. These tests, which rely on probabilistic associations between certain SNPs and multifactorial disease, may well be looked upon as a primitive progenitor of future screening based on whole-genome sequencing. Anyway, the shortcomings of such unselective settings in terms of insufficient diagnostic accuracy, pre-test counselling, and data interpretation have already resulted in critical statements of the German Society of Human Genetics $[3,4]$ and even in a 'cease and desist' letter issued by the State of California's Department of Public Health [5].

Another critical issue is the management of raw or processed sequence data, in particular their protection against improper use. On the one hand, it is in the undoubted interest of any patient to make genetic traits important for emergency medicine, e.g., a $R Y R 1$ mutation conferring a propensity to malignant hyperthermia, readily available to any physician. On the other hand, purely predictive genetic information, like an SOD1 mutation predisposing to amyotrophic lateral sclerosis, must be handled restrictively. The German Society of Human Genetics recently issued a statement recommending a classification of genetic information with respect to their availability through electronic patient records [6]. Still unresolved is the question to what extent probands should be obliged to disclose relevant information generated through whole-genome sequencing to their close genetic relatives [7].

In summary, unselective gathering and uncritical processing of personal DNA sequence data through whole-genome sequencing will in fact generate a too large amount of information with too little value for both patients and physicians. Accordingly, large-scale sequencing in a medical context should always start from a thorough evaluation which individual genome-related health problems are to be addressed, and the subsequent testing must be embedded in a process of pre-test and post-test genetic counselling by a certified medical geneticist [8]. In Germany, the forthcoming Genetic Diagnosis Act (Gendiagnostikgesetz) will demand such a procedure for any kind of predictive genetic testing and prohibit marketing of genetic tests by non-medical professionals outside the health care system. Hopefully, it will be recognized throughout our society that a future 'thousand-dollar genome' purchased anywhere on the grey market tends to generate more concerns than it pretends to resolve.

\section{References}

1 Wilson JMG, Jungner G: Principles and Practice of Screening for Disease. WHO Public Health Paper 1968, No. 34.

2 Wolinsky H: The thousand-dollar genome. Genetic brinkmanship or personalized medicine? EMBO Rep 2007;10:900-903.

3 Deutsche Gesellschaft für Humangenetik: Stellungnahme zur genetischen Diagnostik auf Dispositionsfaktoren für multifaktoriell bedingte Erkrankungen und Entwicklungsstörungen sowie Medikamentenreaktionen. Med Genetik 2004;16:115-117 (English version on www.gfhev.de).
4 Deutsche Gesellschaft für Humangenetik: Kommerzielle Internet-Angebote zur Analyse genetischer SNP-Varianten. Med Genetik 2008;20:237238.

5 Kaye J: The regulation of direct-to-consumer genetic tests. Hum Molec Genet 2008;17:R180-R183.

6 Deutsche Gesellschaft für Humangenetik: Erfassung humangenetischer Patientendaten auf einer elektronischen Gesundheitskarte. Med Genetik 2008; 20:236.
7 McGuire AL, Caulfield T, Cho MK: Research ethics and the challenge of whole-genome sequencing. Nature Rev Genet 2008;9:152-156.

8 Henn W: Schweigepflicht und Datenschutz bei genetischer Beratung - ethische Grundlagen informationeller Selbstbestimmung; in Hirschberg I, Grießler E, Littig B, Frewer A (Hrsg): Ethische Fragen genetischer Beratung. Frankfurt/M., Peter Lang, 2008, pp 103-120. 